\title{
Natural Attenuation of Volatile Hydrocarbons in Unsaturated Soil Zone
}

\author{
P. GrathwohI* and U. Maier
}

\author{
University of Tübingen, Department of Applied Geology, \\ Sigwartstr. 10, D-72076 Tübingen, Denmark
}

\author{
الوهن الطبيعي للهايدروكربونات المتطايرة في التربة غير المشبعة \\ بيتر جراثوول واولي ماير

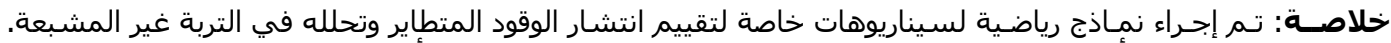

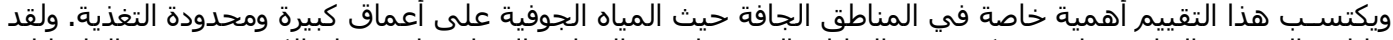

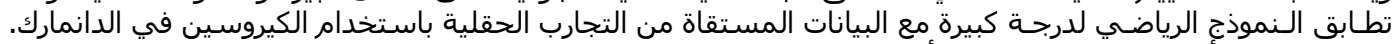

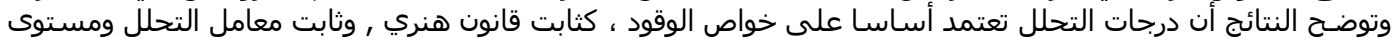 \\ الـرطوبة فـي الـتربة ودرجـات الحربـات الترارة. وفي الإمكان تحديد حركة الملوثات في المياه الجوفية عند فهم عمليات الانتشار \\ هذه في التربة غير المشبعة.
}

\begin{abstract}
Scenario-specific numerical simulations were performed in order to assess the diffusive spreading of volatile fuel constituents and their biodegradation in the unsaturated soil zone. This is especially important in arid regions where the groundwater table is far below the surface and groundwater recharge is limited. The model results compare well with data from a controlled outdoor test with an emplaced source of kerosene. Modelling results illustrate that the overall biodegradation rates depend mainly on properties of the fuel constituents such as Henry's Law constant, on the individual degradation rate constants, the soil water content and temperature. The contaminant transfer rates into groundwater can be determined provided the spreading processes in the unsaturated zone are understood.
\end{abstract}

Keywords: Attenuation, volatile hydrocarbon, unsaturated soil, biodegradation, Henry's law, groundwater, risk assessment.

C ontaminated land poses a serious problem with respect to soil quality and the risk of spreading of pollutants into other compartments of the environment. A major concern at most contaminated sites is the risk of groundwater pollution by organic and inorganic compounds. Since the remediation of all of the contaminated sites is economically not feasible in many countries, groundwater risk assessment procedures are needed for the ranking of sites, decision making on further use and remedial actions. Of special interest is Monitored Natural Attenuation (Wiedemeyer, 1999), that thus far, is mainly applied in polluted aquifers and only to a very limited extent in the unsaturated zone.

At sites where petroleum products are handled or stored, contamination of the unsaturated soil zone is frequently found. Hydrocarbons can reach the groundwater by transport with percolating water and by spreading in soil-gas. Degradation processes can limit the spreading in the unsaturated soil zone and, in the best case, restrict the contamination to the unsaturated zone.

The objective of this study was to use numerical experiments to elucidate the processes/parameters which are relevant in contaminant spreading and thus for groundwater risk assessment. The results are compared to data from a well controlled field test performed at the Værlose Airforce Base, Denmark (Christophersen et al., 2002). Sensitivity analyses were performed accounting for physical-chemical properties of volatile fuel constituents and properties of the soil.

\section{Model}

The numerical model MIN3P (Mayer, 1999) uses the finite volume method and allows for the calculation

*Corresponding author. 
of vapour phase transport and unsaturated flow in the vadose zone. Groundwater transport processes and mass transfer across the capillary fringe can be simulated as well and a variable number of geochemical reactions such as biodegradation processes can be handled (Mayer, 1999). Density driven gas advection was not included in the simulations. It is often considered a significant transport process for compounds with very high vapour pressures in highly permeable materials such as coarse gravel. Hughes-Conant et al. (1996), however, showed that in sandy material, density induced advection is of only minor importance.

The base scenario for the model was adapted to a well controlled field test in Denmark, where a small volume of a multicomponent NAPL (non-aqueous phase liquid) was buried and monitored over a time period of one year (Christophersen et al., 2002). Site characteristics with respect to, for example, grain size distribution, geochemistry, and permeability, were implemented in the model as precisely as possible. The site had a vadose zone of 3.5 meters thickness, consisting of sandy and not too heterogeneous material. The source was emplaced in the subsurface at $1 \mathrm{~m}$ depth. The synthetic hydrocarbon mixture consisted of 13 volatile to semi-volatile kerosene compounds and one tracer (freon). Volatilization and vapour phase diffusion were investigated by Reckhorn et al. (2002). Biodegradation processes were analyzed by Höhener et al. (2002). Monitoring of the contaminant spreading in soil air and groundwater samples in a one-year measurement campaign allowed a comparison to modelled data. A compilation of model input parameters is given in Table 1, and a vertical cross section of the model domain is shown in Figure 1. To reduce computational time, several sensitivity analyses were performed in $1 \mathrm{D}$ and $2 \mathrm{D}$, whereas the model was fitted to field data in 2D and 3D.

\section{Results and Discussion}

The contaminant spreading at the field site and the interactions of 13 kerosene compounds and the tracer could be reproduced reasonably well already by the non-
TABLE 1

Compilation of important parameters of the field site model.

\begin{tabular}{ll}
\hline $\begin{array}{l}\text { Porosity } \\
\text { Volumetric soil } \\
\text { water content }\end{array}$ & $\begin{array}{l}75 \% \\
\text { (top soil } 50 \mathrm{~cm} \text { ) }\end{array}$ \\
$\begin{array}{l}\text { Temperature } \\
15^{\circ} \mathrm{C} \text { (averaged value), and daily } \\
\text { measured data, resp. }\end{array}$ \\
$\begin{array}{l}\text { Groundwater flow } \\
\text { velocity }\end{array}$ \\
$\begin{array}{l}\text { Biodegradation } \\
\text { pseudo first order; rate constants from }\end{array}$ \\
$\begin{array}{l}\text { Diffusion } \\
\text { coefficients }\end{array}$ \\
$\begin{array}{l}8 \cdot 10^{-10} \mathrm{~m}^{2} \mathrm{~s}^{-1} \text { (aqueous) and } 7.3 \cdot 10^{-6} \\
\mathrm{~m}^{2} \mathrm{~s}^{-1} \text { (air) }\end{array}$ \\
$\begin{array}{l}13.61 \text { of kerosene with } 13 \text { compounds } \\
\text { and } 1 \text { tracer (freon CF113) }\end{array}$ \\
\hline
\end{tabular}

calibrated model (pure forward prediction solely based on field and compound parameters). No depletion of $\mathrm{O}_{2}$ was observed even at the source location, which coincides well with the field measurements.

Ageing of the NAPL source results in the enrichment of the lower volatile compounds at the expense of the components with higher vapour pressure, which escape to the atmosphere. The transient evolution of the composition of the NAPL source is shown in Figure 2, which can be regarded as a typical example of kerosene ageing during one year after spill. After 350 days only 5 compounds remain in the residual phase in significant amounts: xylene, tri-methyl-benzene, n-octane, n-decane, n-dodecane and methyl-cyclohexane. The contaminant flux into groundwater is very small compared to volatilisation of source constituents to the atmosphere. As already observed in previous studies (Klenk, 2000; Pasteris et al., 2001) the results show that for VOCs most of the contaminant mass will be degassing to the atmosphere or is subject to biodegradation, whereas only a small fraction diffuses across the capillary fringe into the groundwater (as long as the surface is not sealed). Groundwater

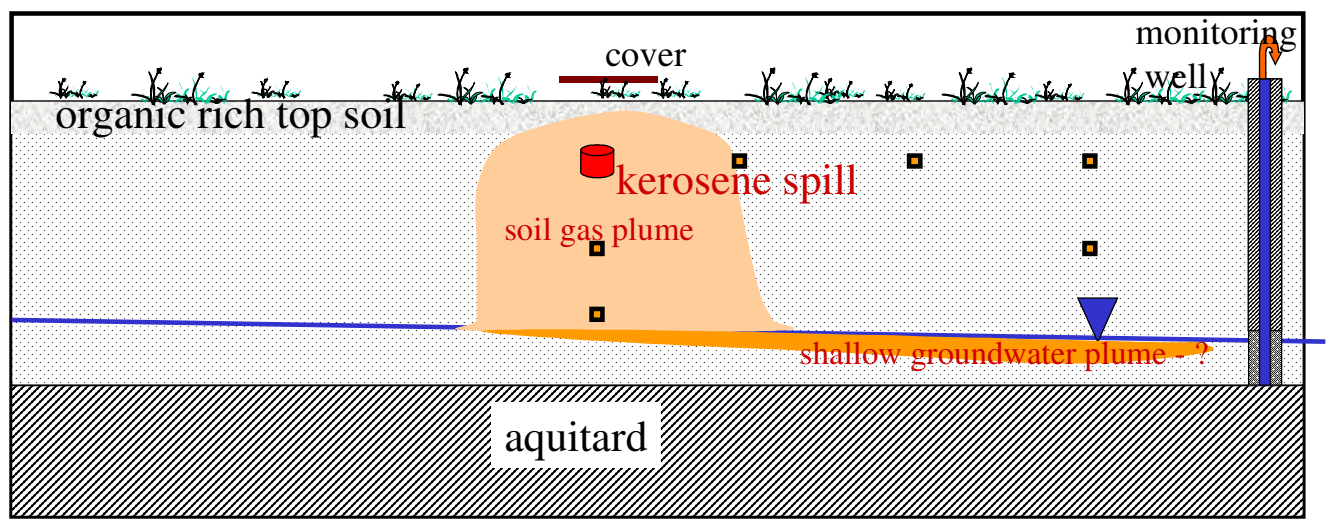

Figure 1: Conceptual model used for sensitivity analysis in numerical simulations. 


\section{NATURAL ATTENUATION OF VOLATILE HYDROCARBONS \\ IN UNSATURATED SOIL ZONE}

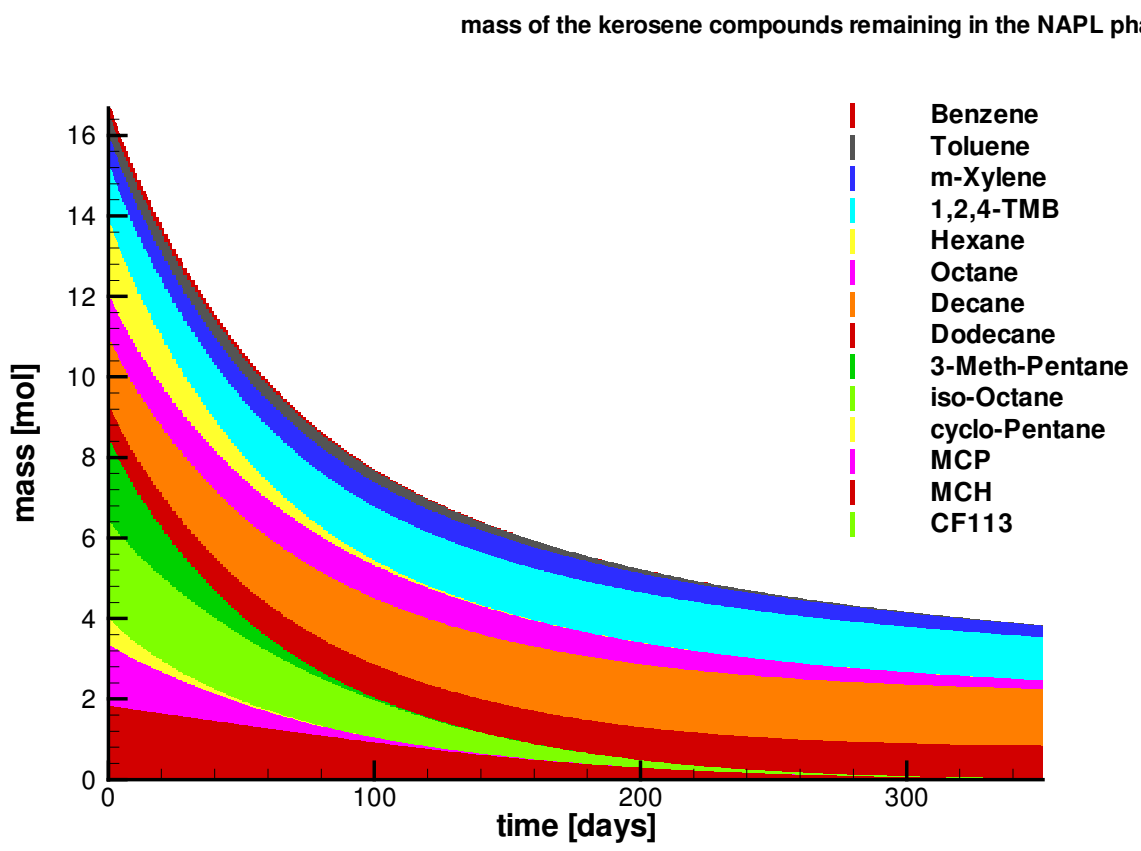

Figure 2: Change of kerosene composition during first year as simulated in 3D model. Sorted in compound classes, from top to bottom, initially: Benzene, Toluene, 1,2,4-Tri-Methyl-Benzene, Hexane, Octane, Decane, 3-Methyl-Pentane, iso-Octane, Cyclo-Pentane, Methyl-Cyclo-Pentane, Methyl-Cyclo-Hexane, and the tracer freon CF113 (only in very small fraction).

recharge is a significant contaminant pathway only in soils with high water content (reduced vapour phase diffusion) and for compounds with low Henry's Law constants (e.g. MTBE in silt or clay). Maximum transport rates into groundwater occurred for the 2 most volatile and soluble compounds toluene and cyclo-pentane. Even in this case only about $0.2 \%$ of the total mass of each compound was transported into the groundwater.

The flux to the atmosphere was most pronounced for the tracer (freon 113), the light alkanes (n-, iso- and cyclo-alkanes) due to their low biodegradation rate constants. Biodegradation was most important for the aromatic compounds (low Henry's law constant) and the heavier n-alkanes (high biodegradation rate constants). According to the model a total mass of $5 \mathrm{~kg} \mathrm{O}_{2}$ was consumed during one year of the experiment leading to production of $\mathrm{CO}_{2}$ and water (oxidation of hydrogen contained in the hydrocarbons).

A view of a vertical cross-section through a $2 \mathrm{D}$ model domain is shown in Fig. 3 for the concentration of iso-octane, which is most concentrated in the original NAPL, at the time of its maximum concentration at the source location. The concentration decreases rapidly from the source zone. Significant contamination extends only in an area of $5 \mathrm{~m}$ in diameter due to biodegradation and volatilisation to the atmosphere.

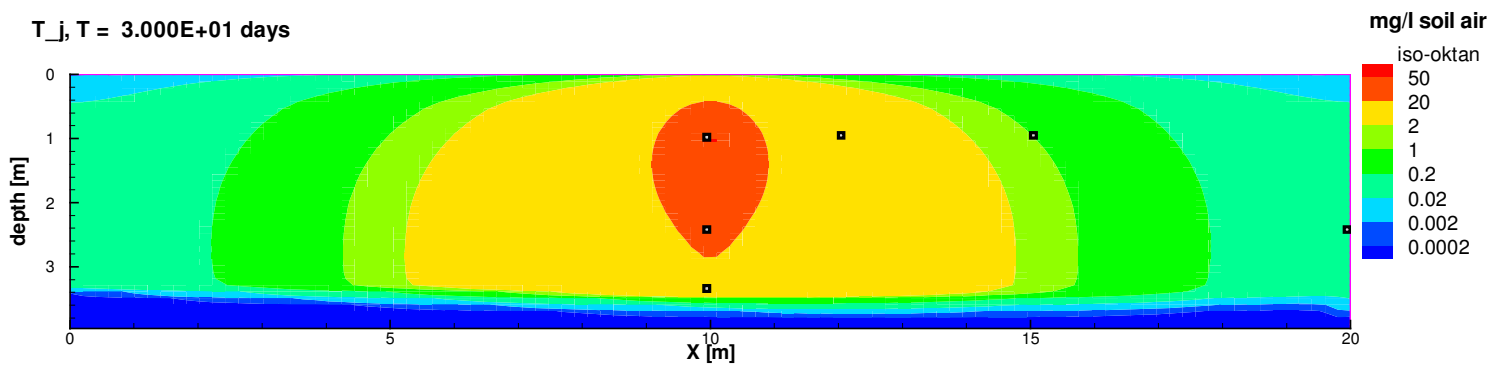

Figure 3: Vertical cross section through model domain for 2D scenario and compound iso-octane 30 days after source installation (time of maximum concentration in source). 


\section{GRATHWOHL AND MAIER}

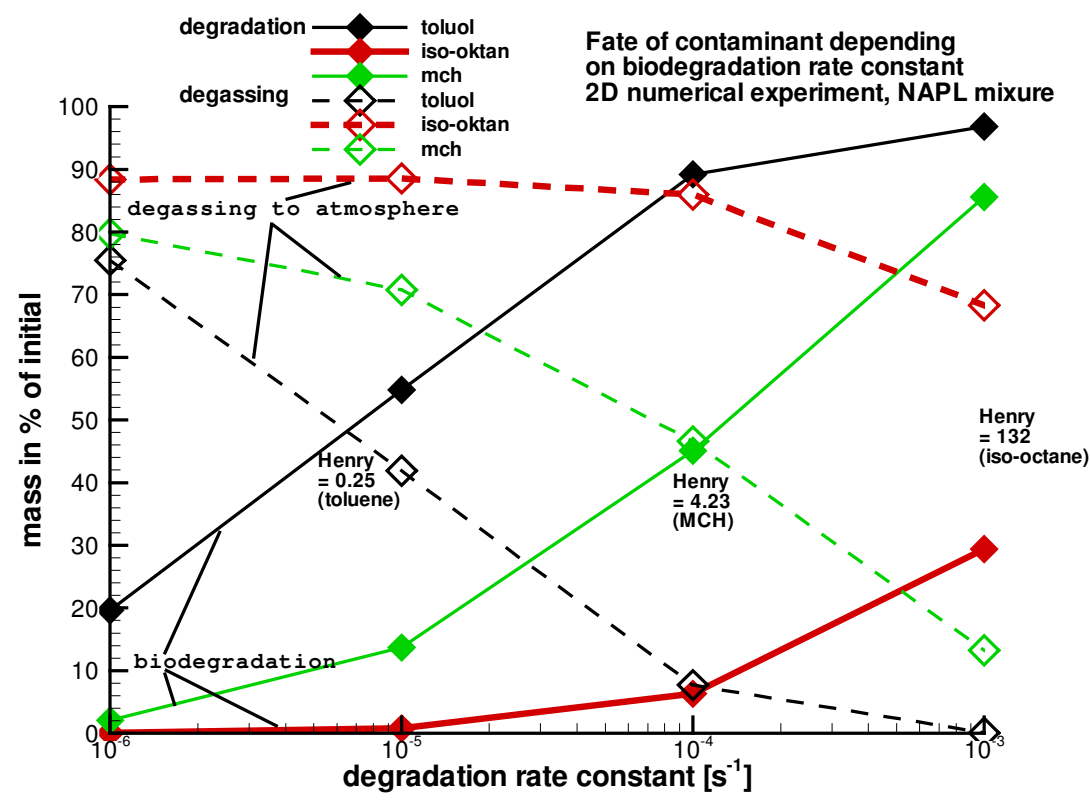

Figure 4: Relation of degassing rate to atmosphere compared to biodegradation rate for three selected compounds with different Henry's law constant $\mathrm{H}$.

\section{Sensitivity Analyses}

To evaluate the importance of soil and meteorological parameters for the contaminant behaviour, sensitivity analyses on biodegradation rate constants, Henry's law constant $H$, aqueous saturation concentration $C_{\text {Sat }}$ for the different compounds, temperature, soil water content and possible anaerobic conditions were conducted in $1 \mathrm{D}$ and $2 \mathrm{D}$.

The overall biodegradation rate depends strongly on Henry's law constant. Highly volatile compounds are slowly degraded (see iso-octane, Figure 4) compared to low $H$ compounds such as BTEX (see toluene in Figure 4 ), because biodegradation takes place only in the aqueous phase.

The ratio of the atmospheric escape to biodegraded mass versus $H$ at a constant degradation rate constant (pseudo first order) is shown in Figure 5. It demonstrates that low $H$ compounds degrade more efficiently. This can be explained by the large fraction of such compounds occurring in the aqueous phase.

fate of contaminant in $\%$ of initial NAPL mass; degr. rate $10^{\wedge}-5 \mathrm{~s}-1$

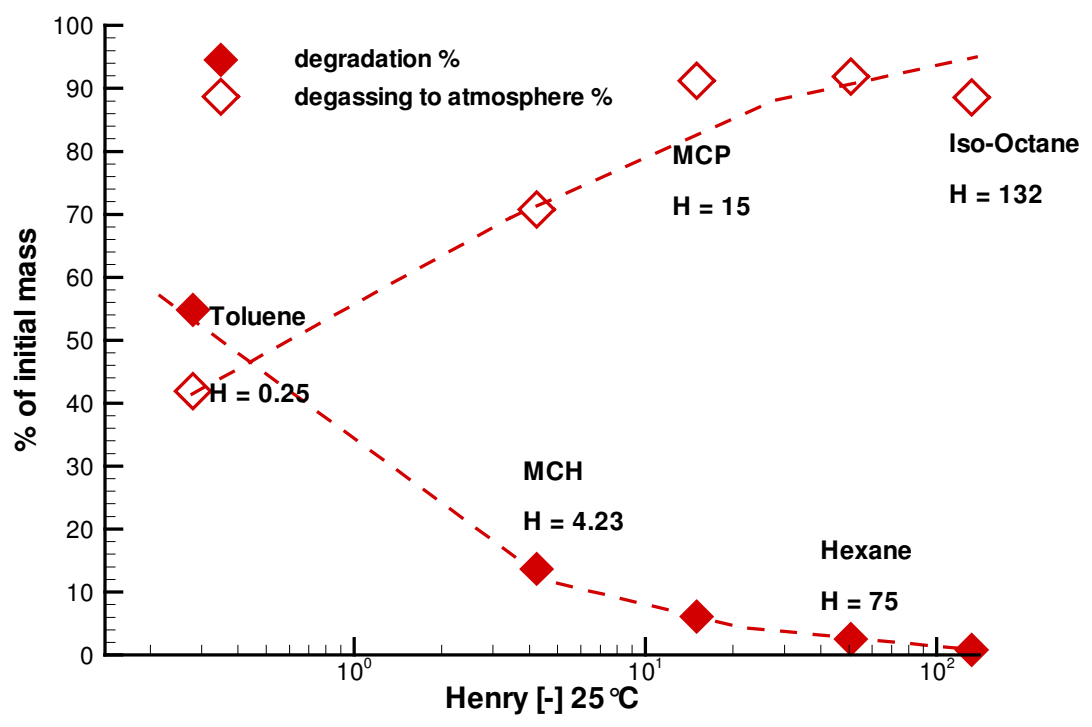

Figure 5: Fate of organic contaminants in relation to Henry's Law constant. A uniform pseudo-first order biodegradation rate constant $=10^{-5} \mathrm{~s}^{-1}$ was applied for all contaminants. GRACOS- Værløse 2D scenario (14 compound mixture), depth of contaminant source $1 \mathrm{~m}$. Henry's law constants from Pasteris et al. (2001). 


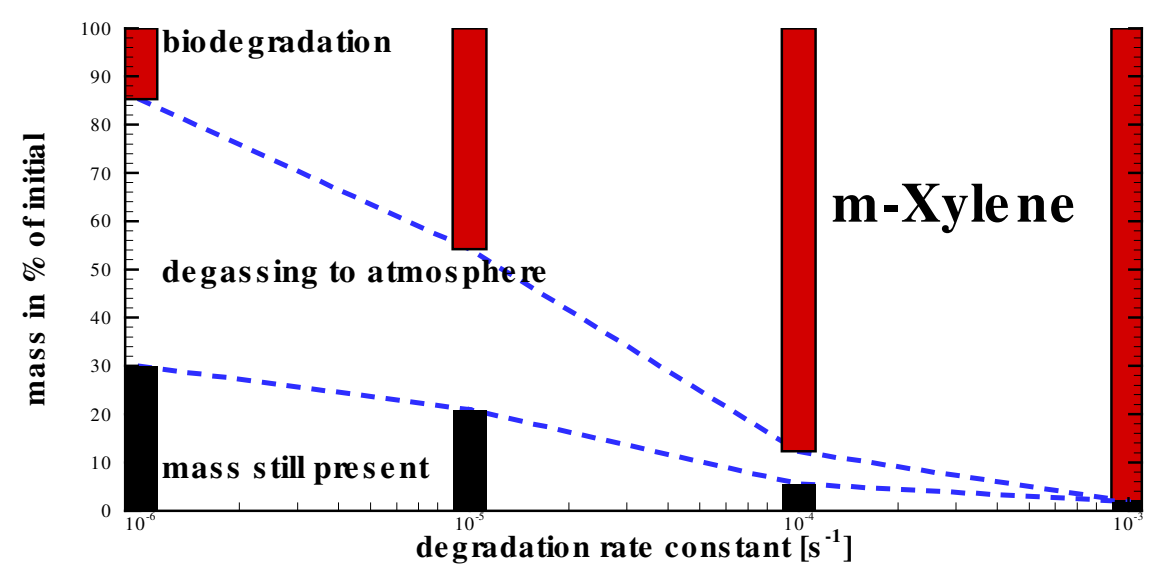

Figure 6: Fate of $m$-xylene in relation to pseudo first order biodegradation rate constant. GRACOS- Værløse 2D scenario (14 compound mixture), depth of contaminant source $1 \mathrm{~m}$.

Depletion of the NAPL phase can be accelerated by rapid biodegradation. This is because the evaporation of the NAPL constituents is enhanced due to steep concentration gradients which are maintained by biodegradation (Figure 6).

Increasing soil water contents reduce the degassing to the atmosphere and thus slightly increase the fraction biodegraded as long as no oxygen limitation occurs. Higher temperatures enhance the volatilisation of the NAPL constituents in general and therefore lead to both, more rapid degassing to the atmosphere and faster biodegradation.

The significance of oxygen depletion at the NAPL source and possible anaerobic degradation scenarios were also tested using the model. Three different anaerobic scenarios can be distinguished: (1) degradation by electron acceptors such as nitrate and sulphate, (2) reduction of iron oxide or manganese oxide containing soil minerals and (3) methanogenesis. Nitrate and sulphate reduction (1) can be neglected due to the low concentrations in rain (Scheffer and Schachtschnabel, 1992). Reduction of oxides (2) can occur e.g. in iron oxide rich soils, but is kinetically limited. Methanogenesis (3) is often observed in heavily contaminated soils if the oxygen supply is restricted. The scenarios required to establish anaerobic conditions were evaluated further as described below.

In a $1 \mathrm{D}$ scenario there is no lateral possibility for oxygen supply and anaerobic conditions can develop quickly, but this scenario is not very realistic for a field case. In a 2D model, the values required for methanogenesis at the field site are constant volumetric water content larger than $14 \%$ (with a porosity of $35 \%$, a benzene fermentation rate constant of $7.8 \times 10^{-6} \mathrm{mg} \mathrm{L}^{-1} \mathrm{~s}^{-1}$ (zero order), a methane oxidation rate constant of $10^{-5}$ $\mathrm{s}^{-1}$ (pseudo first order), and an inhibition threshold of $0.03 \mathrm{mg} / \mathrm{l}$ oxygen). The NAPL source in this scenario contained only benzene, which is highly soluble and fast degassing, i.e. rapidly consuming oxygen (Figure 7). Under this condition, small concentrations of methane

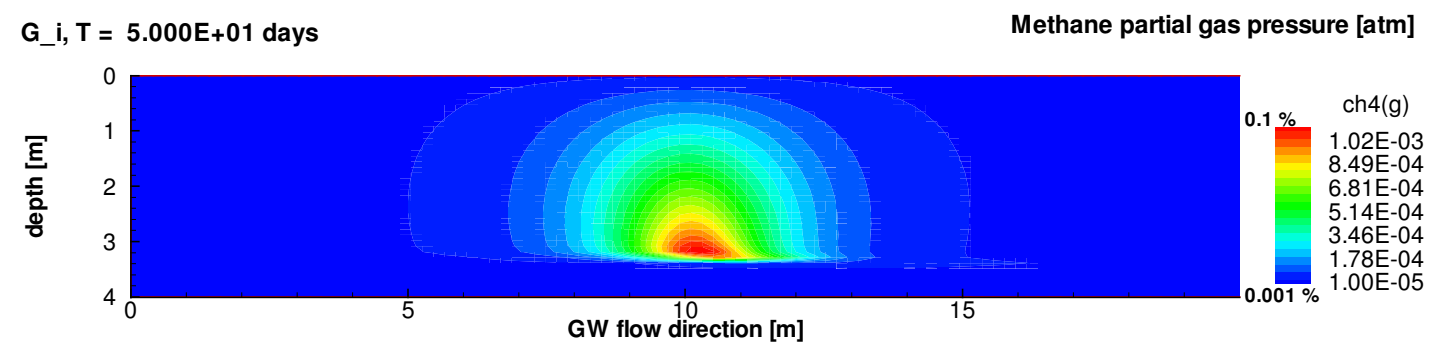

Figure 7: Methane concentration at maximum, 20 days after source installation in 2D simulation. 


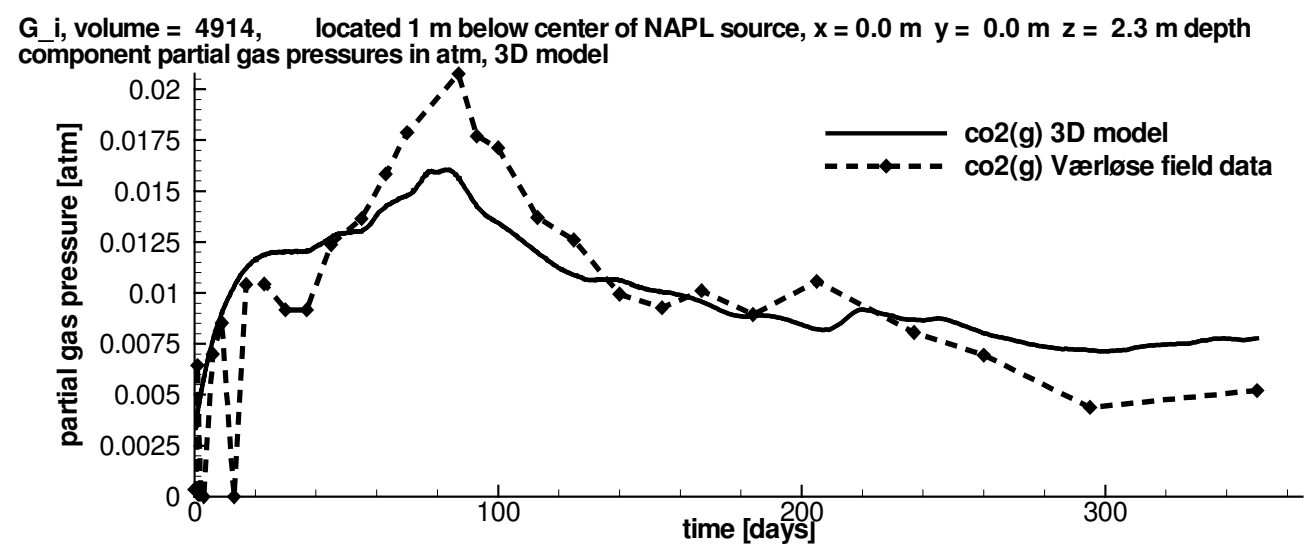

Figure 8: A first comparison of measured and simulated carbon dioxide concentrations at a sampling port $1 \mathrm{~m}$ below the centre of the kerosene source.

$(<1 \%$ Vol.) occur at the capillary fringe below the NAPL source. If soil water contents approach saturation, then the zone of methane formation moves closer to the NAPL source due to faster oxygen.

For the kerosene composition used in the field experiment, however, oxygen depletion was neither predicted by the model nor observed at the field site. Thus, anaerobic conditions can only be expected for fine grained material with high water content or very large, extended NAPL sources, especially if they are deep or close to the groundwater table.

\section{Calibration}

The numerical simulations demonstrated that in the scenario investigated most of the contaminant mass in the unsaturated zone will either be transported to the atmosphere or be subject to biodegradation. Only a very small fraction will diffuse across the capillary fringe and end up in the groundwater. Parameters, which are not measured independently have to be fitted in the model. This will occur most likely for the biodegradation rate constants in the unsaturated zone. After the contaminant spreading in the vadose zone is quantified, mass transfer to groundwater can be evaluated by realistic estimates of transverse vertical dispersion and diffusion in the capillary fringe (see Klenk and Grathwohl, 2002; Eberhardt and Grathwohl, 2002; Gaganis et al., 2002).

If the model accounts for a depth and timedependent temperature field (lower vapour pressures in the winter months), then the agreement with measured data improves significantly compared to constant temperature simulations as shown in Figure 8. A temporally variable unsaturated flow field due to infiltration events results in elevated concentrations of $\mathrm{CO}_{2}$ during longer precipitation periods. This can be explained by higher pore water saturation in the top soil which diminishes the diffusive transport of the biodegradation product to the atmosphere. Figure 8 shows good agreement of field observations with pure forward-modelling. The field experiment is ongoing and more data will be provided in future papers.

\section{Conclusions}

Measured data at the controlled field experiment of a kerosene spill at Vǽrløse field test site, on Natural Attenuation in the unsaturated zone can be reproduced with the numerical model MIN3P. Modelling results illustrate that the overall biodegradation rates depend mainly on distribution parameters such as Henry's Law constant of the fuel constituents, on the biological degradation rate constant, on the soil water content, and on the temperature. The contaminant transfer into groundwater depends on all of these properties and can be determined after quantification of the processes in the unsaturated zone. Results of the field investigations allow the validation of the model, that can then be used to quantify the risk of groundwater contamination for a variety of different scenarios.

\section{References}

Christophersen, M., M. Broholm, and K. Kjeldsen. 2002. Migration and degradation of fuel vapours in the vadose zone. In: Groundwater Risk Assessment at Contaminated Sites. Halm and Grathwohl (eds.). Proceedings of the $1^{\text {st }}$ GRACOS Workshop, Tübingen 22./23.02.02, 83-87.

Eberhardt, C. and P. Grathwohl. 2002. Time scales of pollutants dissolution from complex organic mixtures: blobs and pools Invited Paper for Special Issue of J. Cont. Hydrol. on Site Remediation (in print).

Gaganis, P., E.D. Skouras, M. Theodoropoulou, and V. Burganos. 2002. Modelling contaminant emission across the capillary fringe. In: Groundwater Risk Assessment at Contaminated Sites. Halm \& Grathwohl (eds.). Proceedings of the $1^{\text {st }}$ GRACOS Workshop, Tübingen 22./23.02.02, 119-124. 


\section{NATURAL ATTENUATION OF VOLATILE HYDROCARBONS \\ IN UNSATURATED SOIL ZONE}

Grathwohl, P. and I. Klenk. 2000. Groundwater risk assessment at contaminated sites (GRACOS). In: Contaminated Soil 2000 (12):831-834, W. Harder et al., (eds). Leipzig: Thomas Telford.

Höhener, P., N. Dakhel, D. Werner, and G. Pasteris. 2002. Biodegradation of volatile organic compounds in the unsaturated zone. In: Groundwater Risk Assessment at Contaminated Sites. Halm \& Grathwohl (eds.). Proceedings of the 1st GRACOS Workshop, Tübingen 22./23.02.02, 88-93 .

Hughes-Conant, B, R.W. Gillham, and C.A. Mendoza. 1996. Vapor transport of trichlorethylene in the unsaturated zone: Field and numerical modeling investigations. Water Resources Research 32(1): 9-22.

Klenk, I.D. 2000. Transport of volatile organic compounds (VOC's) from soil-gas to groundwater. PhD Dissertation, TGA, C55, Geological Institute, Tübingen.

Klenk, I.D. and P. Grathwohl. 2002. Transverse vertical dispersion in groundwater and the capillary fringe. J. Cont. Hydrology 58 (1-2):111-128.

Reckhorn, S.B.F., G. Wang, and P. Grathwohl. 2002. Volatilization rates of organic compounds in the unsaturated zone. In: Groundwater Risk
Assessment at Contaminated Sites. Halm \& Grathwohl (eds.). Proceedings of the $1^{\text {st }}$ GRACOS workshop, Tübingen 22./23.02.02, 101-107.

Mayer, K.U. 1999. A multicomponent reactive transport model for variably saturated media. $\mathrm{PhD}$-Thesis at the University of Waterloo, Department of Earth Sciences, Waterloo, Ontario, Canada.

Pasteris, G., D. Werner, K. Kaufmann, and P. Höhener. 2001. Vapor phase transport and biodegradation of volatile fuel compounds in the unsaturated zone: a large scale lysimeter study. Environ. Sci. Technol. submitted.

Scheffer, F. and P. Schachtschabel. 1992. Lehrbuch der Bodenkunde. 13. Auflage, Stuttgart, $491 \mathrm{p}$.

Wiedemeyer, T.H., H.S. Rifai, C.J. Newell, and J.T. Wilson. 1999. Natural Attenuation of Fuels and Chlorinated Solvents in the Subsurface. John Wiley and Sons, New York.

Received September 2002.

Accepted November 2002. 